\section{MMP2 and MMP9 are Associated with Apical Periodontitis Progression and Might be Modulated by TLR2 and MyD88}

Driely Barreiros, Paulo Nelson-Filho, Francisco Wanderley Garcia PaulaSilva, Katharina Morant Holanda de Oliveira, Marília Pacífico Lucisano, Andiara De Rossi, Lea Assed Bezerra Silva, Erika Calvano Küchler, Raquel Assed Bezerra Silva
Department of Pediatric Dentistry, School of Dentistry of Ribeirão Preto, USP - Universidade de São Paulo, Ribeirão Preto, Brazil

Correspondence: Raquel A. B. da Silva, Av. do Café s/n, 14040-904 Ribeirão Preto, SP, Brasil. Tel: 55+16-33154057. e-mail: raquel@forp.usp.br

\begin{abstract}
The aim of this study was to evaluate the expression of MMP2 and MMP9 during apical periodontitis (AP) progression in TLR2 (TLR2 K0) and in MyD88 (MyD88 K0) knockout mice compared to wild type (WT) mice. AP was induced in mandibular first molars of TLR2 KO $(n=18)$, MyD88 KO $(n=18)$, and WT mice $(n=18)$. After 7,21 , and 42 days, the animals were euthanized and the jaws were dissected and subjected to histotechnical processing. Subsequent sections were stained by immunohistochemistry and evaluated for detection of MMP2 and MMP9. Statistical analysis of the semi-quantitative analysis of immunohistochemistry was performed using chi-square test $(\alpha=0.05)$. In the initial periods of AP progression, an increased expression of MMP9 in the TLR2 KO and MyD88 KO mice was observed. In the final periods of AP progression, a reduction of MMP2 expression and an increase of MMP9 expression in the TLR2 K0 mice were observed. MMP2 and MMP9 production was modulated for TLR2 and MyD88 during apical periodontitis progression.
\end{abstract}

Key Words: apical periodontitis, knockout mice, MMPs, MyD88, TLR2.

\section{Introduction}

Apical periodontitis (AP) is an inflammatory alteration of periradicular tissue (1) that results in bone resorption. The association of persistent microbial tooth infection within the root canal system (1), the progression of these microorganisms from the dental pulp to the apical foramen, and the lack of local host immune response leads to AP. During AP, host cells in the periapical tissue release many inflammatory mediators, proinflammatory cytokines, and growth factors through innate and adaptive responses (2).

Toll-like receptors (TLRs) are a Type I transmembrane receptor that present a key role in the innate immune system. TLRs recognize pathogen-associated molecular patterns (PAMPs), such as bacterial or viral components, and endogenous mediators, such as proteins and proinflammatory cytokines (3). Previous studies in experimental animals (4-6) and in humans (7) have demonstrated that TLRs play an important role in the AP pathogenesis.

Toll-like receptor 2 (TLR2) recognizes lipoproteins/ lipopeptides from different pathogens and peptidoglycans and lipoteichoic acid from gram-positive bacteria, which there upon triggers inflammatory signals in innate immune cells (3). Recognition of a microbial invasion through the TLRs, including TLR2, triggers the activation of signaling pathways, resulting in the recruitment of several adaptor proteins to the Toll/IL-1 receptor (TIR) domain. Myeloid differentiation factor 88 (MyD88), an adapter molecule, which is common to almost all TLRs except TLR3, triggers the activation of protein kinases and transcription factors that stimulate the expression of genes which are involved in the inflammatory response (8). The recent study from our research group demonstrated that MyD88 knockout mice had larger AP, suggesting the role of this factor in AP progression (5).

Matrix metalloproteinases (MMPs) are mostly secreted enzymes that belong to a family of zinc- and calciumdependent proteolytic enzymes that are known to degrade most components of the extracellular matrix (ECM) (9). MMPs are strongly associated with levels of inflammation and play a major role in bone remodeling and bone resorption (10). MMP2 participates in the remodeling and resolution of tissue injury (11) and infection clearance (12). On the other hand, MMP9 is a multidomain enzyme functioning in acute and chronic inflammatory condition (13). It is essential for initiating the osteoclastic resorption process by removing the collagenous layer from the bone demineralization (14). MMP2 and MMP9 are known to specifically cleave Type IV collagen, which is a major structural component of the basal membrane (15).

Some evidences suggested that MMPs are involved in AP development and play an important role in the pulp and periapical tissue destruction during inflammation process (16). In particular, MMP2 and MMP9 expression has been consistently reported in $\operatorname{AP}(16,17)$. 
Some studies support the interaction between TLR2 and MMPs. TLR2 up-regulates MMP2 and MMP9 in glioma stem cells (18) and up-regulates MMP9 in monocytic cells (19). Although the interaction between these proteins has been previously investigated, their role in AP progression is still unexplored. Therefore, the aim of this study was to evaluate the expression of MMP2 and MMP9 during AP progression in TLR2 (TLR2 K0) and MyD88 (MyD88 K0) knockout mice, compared to wild type (WT) mice.

\section{Material and Methods}

\section{Animals}

Animal procedures were performed in accordance with the ethical guidelines of the Ethics Committee of the Campus of Ribeirão Preto of the University of São Paulo (\# 11.1.91.53.0 and 2014.1.911.58).

Male wild type (WT) C57BL/6 ( $\mathrm{n}=18$ animals), TLR2 KO B6.129-TLR2 ${ }^{\text {tm } 1 \text { kir/J }}(\mathrm{n}=18$ animals), and MyD88 KO C57BL/6 mice ( $\mathrm{n}=18$ animals), with ages ranging 6 to 8 weeks, were used. The WT mice were obtained from the Animal Facility of the School of Dentistry of Ribeirão Preto, University of São Paulo, Brazil, and the TLR2 KO and MyD88 KO mice were obtained from the Animal Facility of the Department of Genetics of the Medical School of Ribeirão, University of São Paulo, Brazil, which originally obtained them from The Jackson Laboratory, Bar Harbor, Maine - EUA.

\section{Apical Periodontitis Induction}

Briefly, the mice were anaesthetized by an intramuscular injection of 10\% ketamine hydrochloride $(150 \mathrm{mg} / \mathrm{kg}$; Agener União Química Farmacêutica Nacional S/A, EmbuGuaçu, São Paulo, Brazil) and 2\% xylazine hydrochloride (7.5 mg/kg; Dopaser, Laboratórios Calier, SA, Barcelona, Spain) in the thigh and mounted on a jaw retraction board.

Stainless steel 1/4 round burs (GDK Densell Dental Technology, Buenos Aires, Argentina) in a low-speed hand piece were used to access the pulp chamber of the mandibular first molars. The distal root canal was localized with a sterile size $08 \mathrm{~K}$-file (Dentsply Maillefer, Ballaigues, Switzerland) and the penetration of depth was done until reach resistance (approximately up to the medial third). The pulp chamber was completely removed and left exposed to the oral cavity for AP induction (4).

The animals were randomly euthanized at three different periods: on days 7,21 , and 42 in a $\mathrm{CO}_{2}$ chamber.

\section{Histotechnical Processing}

After euthanasia, the lower jaws were removed, fixed in 10\% phosphate-buffered formalin for $24 \mathrm{~h}$ and, for the decalcification of the pieces, a solution based on EDTA at $4.13 \%$ (pH 7-7.4) was used, where the specimen were kept for approximately 1 month. After, samples were submitted to routine histotechnical processing. Longitudinal $5-\mu m$-thick semi-serial sections were cut in a mesiodistal orientation throughout the AP. HE staining of these samples was demonstrated in the previous works of our group $(4,5)$

\section{Immunohistochemistry}

The immunohistochemistry was performed according to a previously published protocol (4). The slide was selected every 3 slides from the beginning of the AP in to the end of the AP. The slides were incubated overnight with the primary antibodies diluted in 1\% BSA: anti-MMP2 (polyclonal goat K-20 sc-8835 Santa Cruz Biotechnology Inc., Santa Cruz, CA, USA, diluted 1:100) and anti-MMP9 (polyclonal goat C-20 sc-6840 Santa Cruz Biotechnology Inc., Santa Cruz, CA, USA, diluted 1:100). After returning to room temperature and washing, the slides were incubated with a biotinylated secondary antibody (goat anti-rabbit IgG-B sc-2040, Santa Cruz Biotechnology Inc., diluted 1:200) for $1 \mathrm{~h}$ at room temperature. The streptavidinbiotin-peroxidase complex (ABC kit, Vecstain; Vector Laboratories Inc.) was then added for $30 \mathrm{~min}$, followed by chromogen 3,3' diaminobenzidine tetrahydrochloride hydrate (DAB; Sigma-Aldrich Corp., St. Louis, MO, USA), added with $3 \%$ hydrogen peroxide in PBS for $1 \mathrm{~min}$. The slides were counterstained with Harris Haematoxylin. The results, were evaluated by a pre-calibrated blind examiner, and were expressed as semi-quantitative data considering the intensity of the DAB chromogen throughout the periapical lesion area (absence, mild, moderate, or intense) for MMP2 and MMP9.

\section{Statistical Analysis}

The statistical analysis was performed using the Epi-Info 7.0 software (Epi Info ${ }^{\mathrm{TM}}$, Atlanta, GA - USA). Chi-square test was used to analyze the semi-quantitative results of the immunohistochemistry. A significance level of 5\% was set for all analyses.

\section{Results}

Immunostaining was analyzed in the AP and, coincidentally, immunostaining of both MMP2 and MMP9 were present throughout the AP extent independent of $D A B$ chromogen intensity. The semi-quantitative analysis of the immunohistochemistry results showed a statistically significant difference in the MMP2 expression among WT, TLR2 K0, and MyD88 KO groups after 42 days $(\mathrm{p}=0.01)$ (Table 1). Of note, at 42 days, lower intensity of immunostaining was observed in TLR2 KO mice (Fig. 1).

In the analysis of the MMP9 expression, a statistically significant difference among WT, TLR2 KO and MyD88 KO 
groups at $7(p=0.01)$ and 42 days $(p=0.03)$ was observed (Table 2). Specifically at 7 days, both TLR2 and MyD88 KO mice presented more intense production of MMP9, whereas at 42 days, solely TLR2 K0 mice sustained higher MMP9 synthesis (Figure 2).

In the initial periods of AP progression an increased expression of MMP9 in the TLR2 KO and MyD88 KO mice was observed. In the final periods of AP progression, a reduction of MMP2 expression and an increase of MMP9 expression in the TLR2 KO was observed.

\section{Discussion}

In the present study, we decided to use knockout mice for TLR2 and MyD88 as a biological model. Knocking out the activity of TLR2 and MyD88 allowed us to understand the interaction between MMP9 and MMP2 with these proteins providing valuable clues regarding AP progression.

Previous studies performed in rats (20) and humans (21) suggested that MMP2 and MMP9 could be acting in the ECM degradation, favoring the lesion progression, and together with other cytokines, contributing to bone destruction in apical periodontitis. MMP2 modulates many physiological conditions including wound repair and tissue remodeling (22). In physiological condition, MMP2 is expressed by periodontal ligament cells (23) and acts in response to infection, tissue remodeling and injury. In our study, we observed that MMP2 expression was lower in the TLR2 KO mice than in the WT at 42 days. A previous study in glioma stem cells also demonstrated that TLR2 up-regulates MMP2 expression (18).

Table 1. Semi-quantitative immunohistochemistry data from MMP2

\begin{tabular}{lcccc}
\hline Animal & Mild $n(\%)$ & Moderate $n(\%)$ & Intense $n(\%)$ & $\mathrm{p}$ value \\
\hline 7 days & & & & \\
WT & 0 & $3(50.00)$ & $3(50.0)$ & Reference \\
TLR2 & $2(33.4)$ & $3(50.00)$ & $1(16.7)$ & 0.22 \\
MyD88 & 0 & $3(50.00)$ & $3(50.00)$ & 1.00 \\
21 days & & & & \\
WT & 0 & $2(33.4)$ & $4(66.7)$ & Reference \\
TLR2 & 0 & $4(66.7)$ & $2(33.4)$ & 0.37 \\
MyD88 & $1(16.7)$ & $2(33.4)$ & $3(50.0)$ & 0.63 \\
42 days & & & & \\
WT & 0 & $2(33.4)$ & $4(66.7)$ & Reference \\
TLR2 & $4(66.7)$ & $2(33.4)$ & 0 & 0.01 \\
MyD88 & 0 & $2(33.4)$ & $4(66.7)$ & 1.00 \\
\hline
\end{tabular}

Chi-square test was used $(\mathrm{p}<0.05)$.
MMP9 is predominantly produced by monocytes/ macrophages that abound in sites of chronic inflammation, such as periodontal disease, in which the connective tissue degradation by MMP9 is considered to trigger the disease pathology (24). MMP9 is also essential for initiating the osteoclastic resorption process by removing the collagenous layer from the bone surface before demineralization can start (14). An interaction between TLR2 and MyD88 with MMP9 has also been demonstrated in monocytic cells (25). In our study, we noted that the expression of MMP9 in both $\mathrm{KO}$ mice were different from the WT. The expression of MMP9 in both KO mice was higher than WT, by which we can hypothesize that TLR2 and MyD88 present a protective role in AP because in their absence MMP9 expression was increased during AP progression.

It is important to emphasize that some previous studies demonstrated that TLR2 is involved in the response to a variety of bacterial components. Bacterial infection is a condition for the development of periapical lesions when it is derived from extensive carious lesions. MMP9 production was enhanced in human pulp and periodontal ligament cells stimulated with endodontic pathogens (23).

Studies using animal model has some obvious limitations, including the fact that AP rarely occurs spontaneously in mice. In addition, in humans, knockout of a entire gene is uncommon, therefore, knockout mice is a tool to understand the function of a target gene in the studied pathological condition, which lead some results specific to a condition of the absence of the gene. Also, in knockout mice, the wild type is used as control once they

Table 2. Semi-quantitative immunohistochemistry data from MMP9

\begin{tabular}{lcccc}
\hline Animal & Mild $n(\%)$ & Moderate $n(\%)$ & Intense $n(\%)$ & $\mathrm{p}$ value \\
\hline 7 days & & & & \\
WT & $5(83.4)$ & $1(16.7)$ & 0 & Reference \\
TLR2 & 0 & $5(83.4)$ & $1(16.7)$ & 0.01 \\
MyD88 & $1(16.7)$ & $5(83.4)$ & 0 & 0.02 \\
21 days & & & & \\
WT & $4(66.7)$ & $2(33.4)$ & 0 & Reference \\
TLR2 & $1(16.7)$ & $4(66.7)$ & $1(16.7)$ & 0.17 \\
MyD88 & $1(16.7)$ & $4(66.7)$ & $1(16.7)$ & 0.17 \\
42 days & & & & \\
WT & $4(66.7)$ & $2(33.4)$ & 0 & Reference \\
TLR2 & 0 & $3(50.0)$ & $3(50.0)$ & 0.02 \\
MyD88 & $2(66.7)$ & $4(33.4)$ & 0 & 0.24 \\
\hline
\end{tabular}

Note: Chi-square was used $(\mathrm{p}<0.05)$. 


\section{MMP 2}

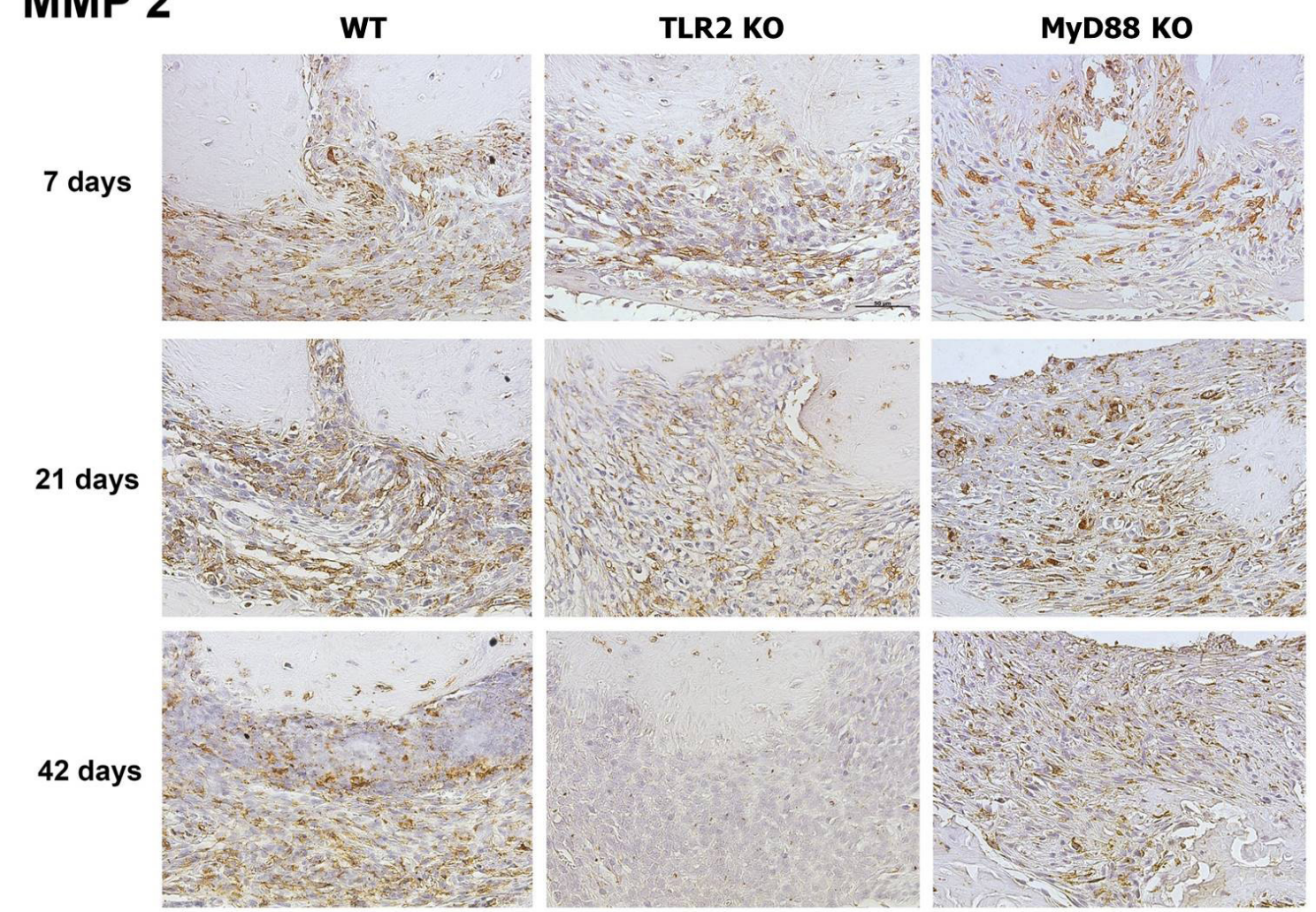

Figure 1. Representative photomicrographs obtained 7, 21 and 42 days after the experimental induction of periapical lesions in WT, TLR2 K0 and MyD88 K0 mice for the observation of MMP2 stained by immunohistochemistry (40 magnifications).

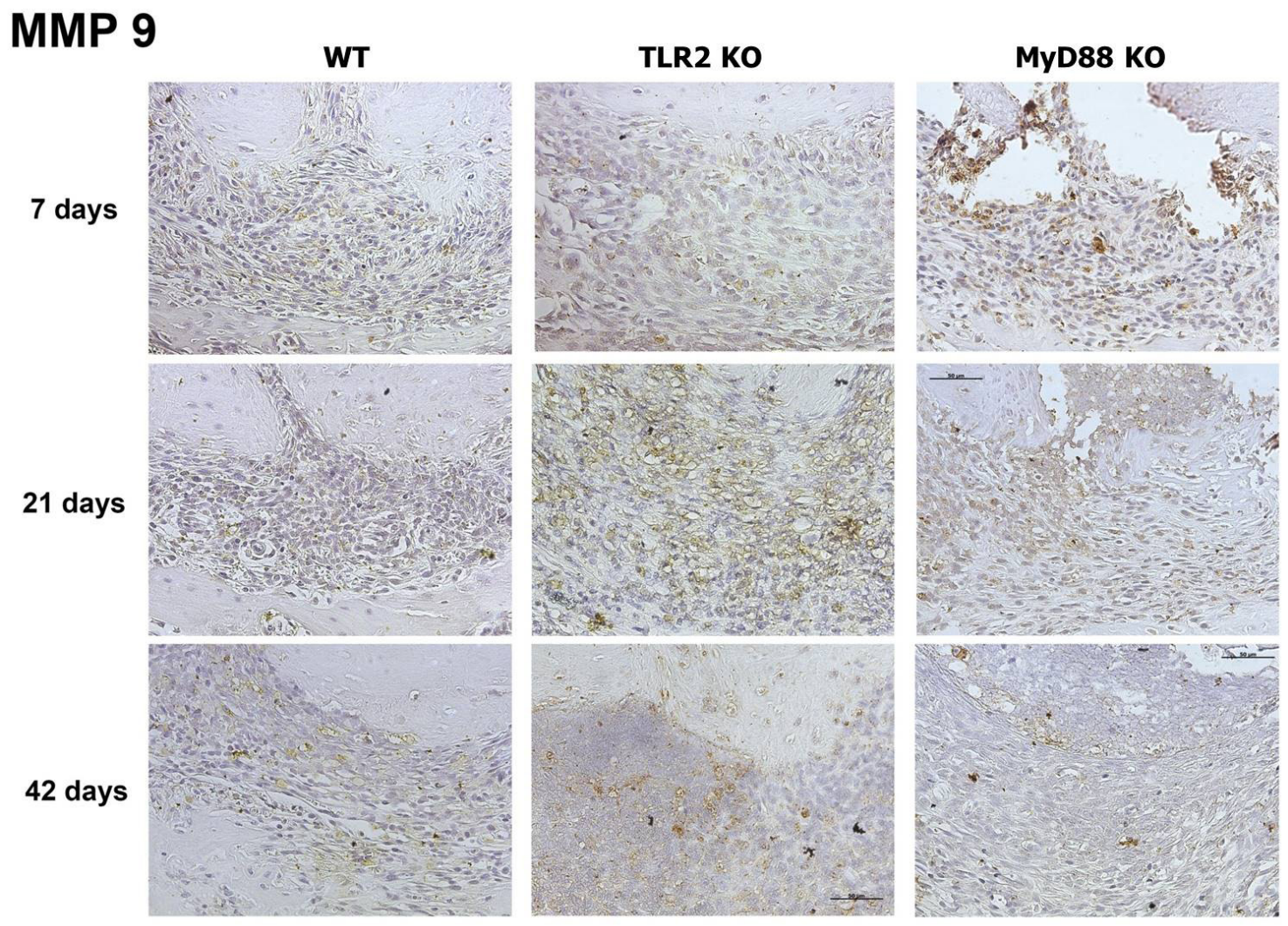

Figure 2. Representative photomicrographs obtained 7, 21 and 42 days after the experimental induction of periapical lesions in WT, TLR2 K0 and MyD88 K0 mice for the observation of MMP9 stained by immunohistochemistry (40 magnifications). 
are originated for the same lineage (C57BL/6).

Although many studies have evaluated a large variety of molecules in the AP context, the role of TLR2, MyD88, MMP2, and MMP9 over dissemination of infection, pulpal necrosis, and AP progression is not completely understood. Our study added some new important information regarding the molecules involved in the progression of the AP. However, further studies should be performed in animals and humans to better understand the association between bacteria, MMPs, and innate immune system.

In conclusion, MMP2 and MMP9 production was modulated by TLR2 and MyD88 during apical periodontitis progression.

\section{Resumo}

0 objetivo deste estudo foi avaliar a expressão de MMP2 e MMP9 durante a progressão da periodontite apical (AP) em camundongos knockout para TLR2 (TLR2 K0) e MyD88 (MyD88 K0) comparados aos camundongos wild type (WT). A AP foi induzida nos primeiros molares inferiores dos camundongos TLR2 KO $(n=18)$, MyD88 KO $(n=18)$ e WT $(n=18)$. Após 7, 21 e 42 dias, os animais foram eutanaziados e as mandibulas foram dissecadas e submetidas a processamento histotécnico. As lâminas foram coradas por imuno-histoquimica e analisadas para a detecção de MMP2 e MMP9. A análise estatistica semi-quantitativa da imuno-histoquímica foi realizada pelo teste qui-quadrado $(\alpha=0,05)$. Nos períodos iniciais de progressão AP, foi observada uma expressão aumentada de MMP9 nos camundongos TLR2 KO e MyD88 KO. Nos periodos finais de progressão $A P$, observou-se uma redução da expressão de MMP2 e um aumento da expressão de MMP9 nos camundongos TLR2 KO. A produção de MMP2 e MMP9 foi modulada por TLR2 e MyD88 durante a progressão da periodontite apical.

\section{Reference}

1. Kakehashi S, Stanley HR, Fitzgerald RJ. The effects of surgical exposures of dental pulps in germfree and conventional laboratory rats. Oral Surg Oral Med Oral Pathol 1965;20:340-349.

2. Lin LM, Huang GT, Rosenberg PA. Proliferation of epithelial cell rests, formation of apical cysts, and regression of apical cysts after periapical wound healing. J Endod 2007;33:908-916.

3. Takeda K, Akira S. Toll-like receptors in innate immunity. Int Immunol 2005;17:1-14.

4. Silva RA, Ferreira PD, De Rossi A, Nelson-Filho P, Silva LA. Toll-like receptor 2 knockout mice showed increased periapical lesion size and osteoclast number. J Endod 2012;38:803-813.

5. Bezerra da Silva RA, Nelson-Filho P, Lucisano MP, De Rossi A, Queiroz AM, Bezerra da Silva LA. MyD88 knockout mice develop initial enlarged periapical lesions with increased numbers of neutrophils. Int Endod J 2014;47:675-686.

6. Rider D, Furusho $H, X u S$, Trachtenberg AJ, Kuo WP, Hirai $K$, et al.. Elevated CD14 (Cluster of Differentiation 14) and Toll-Like Receptor (TLR) 4 Signaling Deteriorate Periapical Inflammation in TLR2 Deficient Mice 2016;299:281-292.

7. Özan Ü, Ocak Z, Özan F, Oktay EA, Toptaş O, Şahman H, et al. Association of Toll-like receptors 2, 3, and 4 genes polymorphisms with periapical pathosis risk. Med Oral Patol Oral Cir Bucal 2016;21:e408-e412.

8. Gomes MT1, Campos PC, de Almeida LA, Oliveira FS, Costa MM, Marim
FM, et al. The role of innate immune signals in immunity to Brucella abortus. Front Cell Infect Microbiol 2012;2:1-9.

9. Murphy G. Matrix metalloproteinases and their inhibitors. Acta Orthop Scand Suppl 1995;266:55-60.

10. Hill PA, Murphy G, Docherty AJ, Hembry RM, Millican TA, Reynolds JJ, et al. The effects of selective inhibitors of matrix metalloproteinases (MMPs) on bone resorption and the identification of MMPs and TIMP-1 in isolated osteoclasts. J Cell Sci 1994;07:3055-3064.

11. Brooks PC, Silletti $S$, von Schalscha TL, Friedlander M, Cheresh DA Disruption of angiogenesis by PEX, a noncatalytic metalloproteinase fragment with integrin binding activity. Cell 1998;92:391-400.

12. Lima AC, Francelin C, Ferrucci DL, Stach-Machado DR, Verinaud L. Thymic alterations induced by Plasmodium berghei: expression of matrix metalloproteinases and their tissue inhibitors. Cell Immunol 2012;279:53-59.

13. Buzoglu $H D$, Unal $H$, Ulger $C$, Mert $S$, Kücükyildirim $S$, Er N. The zymographic evaluation of gelatinase (MMP- 2 and -9) levels in acute and chronic periapical abscesses. Oral Surg Oral Med Oral Pathol Oral Radiol Endod 2009;108:e121-6.

14. Delaissé JM1, Engsig MT, Everts V, del Carmen Ovejero M, Ferreras $M$, Lund $L$, et al. Proteinases in bone resorption: obvious and less obvious roles. Clin Chim Acta 2000;291:223-234.

15. Corotti MV, Zambuzzi WF, Paiva KB, Menezes R, Pinto LC, Lara VS, et al. Immunolocalization of matrix metalloproteinases-2 and -9 during apical periodontitis development. Arch Oral Biol 2009;54:764-771.

16. Campos $K$, Franscisconi CF, Okehie V, de Souza LC, Trombone AP, Letra $A$, et al.. FOXP3 DNA methylation levels as a potential biomarker in the development of periapical lesions. J Endod 2015;41:212-218.

17 Paula-Silva FW, da Silva LA, Kapila YL. Matrix metalloproteinase expression in teeth with apical periodontitis is differentially modulated by the modality of root canal treatment. J 18 . Endod 2010;36:231-237.

18. Wang $F$, Zhang $P$, Yang $L, Y u X, Y e X$, Yang J, et al.. Activation of toll-like receptor 2 promotes invasion by upregulating MMPs in glioma stem cells. Am J Transl Res 2015;7:607-615.

19. Shihab PK, Al-Roub A, Al-Ghanim M, Al-Mass A, Behbehani K, Ahmad R. TLR2 and AP-1/NF-kappaB are involved in the regulation of MMP-9 elicited by heat killed Listeria monocytogenes in human monocytic THP-1 cells. J Inflamm 2015;12:32.

20. Kawashima N, Suzuki N, Yang G, Ohi C, Okuhara S, Nakano-Kawanishi H, et al.. Kinetics of RANKL, RANK and OPG expressions in experimentally induced rat periapical lesions. Oral Surg Oral Med Oral Pathol Oral Radiol Endod 2007;103:707-711.

21. Menezes $R$, Garlet TP, Letra $A$, Bramante $C M$, Campanelli AP, Figueira Rde $C_{\text {, et al... Differential patterns of receptor activator of nuclear }}$ factor kappa B ligand/osteoprotegerin expression in human periapical granulomas: possible association with progressive or stable nature of the lesions. J Endod 2008;34:932-938.

22. Godefroy E, Gallois A, Idoyaga J, Merad M, Tung N, Monu N, et al. Activation of toll-like receptor-2 by endogenous matrix metalloproteinase-2 modulates dendritic-cell-mediated inflammatory responses. Cell Rep 2014;9:1856-1870.

23. Chang $Y$, Lai $C$, Yang $S$, Chan $Y$, Hsieh $Y$ Stimulation of matrix metalloproteinases by black-pigmented Bacteroides in human pulp and periodontal ligament cell cultures. J Endod 2002;28:90-93.

24. Devereux G, Steele $S$, Jagelman T, Fielding S, Muirhead R, Brady J, et al. An observational study of matrix metalloproteinase (MMP)- 9 in cystic fibrosis. J Cyst Fibros 2014;13:557-563.

25. Ahmad R, Shihab PK, Jasem S, Behbehani K. FSL-1 induces MMP-9 production through TLR-2 and NF-KB/AP-1 signaling pathways in monocytic THP-1 cells. Cell Physiol Biochem 2014;34:929-942.

Received May 28, 2017 Accepted November 21, 2017 